\title{
One stage resection of spontaneous rupture of hepatocellular carcinoma in the triangular ligament with diaphragm invasion: case report and review of the literature
}

\author{
Kwang-Kuk Park, Song-I Yang and Myung-hee Yoon
}

\begin{abstract}
A spontaneous rupture of hepatocellular carcinoma (HCC) can lead to extensive hemorrhage and is a rare but life-threatening event. A 58-year-old male patient with no history of trauma presented at our institution with severe epigastric pain and abdominal distension for $6 \mathrm{~h}$. His blood pressure was a 60/40 $\mathrm{mmHg}$, and pulse rate was 132/min. Abdominal contrast enhanced computed tomography (CT) imaging revealed a ruptured mass under the left diaphragm and fluid collection in the upper abdomen, flanks and pelvic cavity. Exploratory laparotomy confirmed the presence of an active bleeding tumor in the triangular ligament invading into the diaphragm. The tumor was resected with an appropriate diaphragm margin. The resected tumor was $5 \mathrm{~cm}$ in diameter and pathologically identified as hepatocellular carcinoma with a negative surgical margin. This case report shows that ruptured hepatocellular carcinoma should be considered in the differential diagnosis of non-traumatic hemoperitoneum. And it is necessary to set a surgical plan for unpredictable HCC rupture with direct diaphragm invasion.
\end{abstract}

Keywords: Spontaneous rupture, Hepatocellular carcinoma, Hemoperitoneum

\section{Introduction}

Hepatocellular carcinoma (HCC) is the fifth most common type of cancer diagnosed worldwide and the third leading cause of cancer-related mortality [1,2]. Spontaneous rupture is reported to occur in $3-15 \%$ of cases and is one of the most severe complications of HCC [3-5]. The prognosis for spontaneous rupture of $\mathrm{HCC}$ is poor, with a hospital mortality rate ranging from 33 to $67 \%$ [6-8]. However, clinical diagnosis of this HCC complication is difficult due to its atypical symptoms. For example, some patients may present with abdominal pain, abdominal distension and anemia, while others suffer from shock as the initial symptom. Furthermore, treatment of HCC is complicated by co-morbidities, coagulopathy, hemorrhagic shock, liver cirrhosis, and decreased liver function. A peripherally located large HCC lesion is clinically prone to grossly involve the diaphragm, either by dense adhesion or as a result of

\footnotetext{
* Correspondence: yoonmhj@dreamwiz.com

Department of Surgery, Kosin University College of Medicine, Busan, South
} Korea

\section{Biomed Central}

(C) 2012 Park et al.; licensee BioMed Central Ltd. This is an Open Access article distributed under the terms of the Creative Commons Attribution License (http://creativecommons.org/licenses/by/2.0), which permits unrestricted use, distribution, and reproduction in any medium, provided the original work is properly cited.

\section{Case report}

A 58-year-old man visited the emergency department with hypovolemic shock. His chief complaint was the sudden onset of epigastric pain with abdominal distension lasting $6 \mathrm{~h}$. Physical examination revealed an ill appearance with a blood pressure of $60 / 40 \mathrm{mmHg}$ and a pulse rate of $132 / \mathrm{min}$. Conjunctiva were pale but not icteric. Breath sounds were clear, and heart sounds were regular and without murmurs. The patient had negative history of hepatitis $B$, hepatitis $C$ or trauma. Hemoglobin 
was $6.9 \mathrm{~g} / \mathrm{dl}$, white blood count was $15,800 / \mathrm{mm} 3$ and platelet count was $176,000 / \mathrm{mm}^{3}$. Liver function tests were within the normal range [serum alanine transaminase 35 IU/1 (normal: 5-40 IU/l), serum aspartate transaminase 18 IU/l (normal: 8-40 IU/l), gamma glutamyltranspeptidase $16 \mathrm{IU} / \mathrm{l}$ (normal:<30 IU/l), alkaline phosphatase $38 \mathrm{IU} / \mathrm{l}$, total billibubin $0.6 \mathrm{mg} / \mathrm{dl}$, direct billibubin $0.3 \mathrm{mg} / \mathrm{dl}]$. Prothrombin time and International Normalized Ratio (INR) were prolonged with prothrombin time of $16.4 \mathrm{~s}$ (normal: 10.2 - 13.6), and INR of 1.43 (PT ratio). Abdominal contrast enhanced $\mathrm{CT}$ imaging revealed a mass invading the diaphragm with contrast extravasation in the left, lateral segment of the liver (Figure 1, and Figure 2). Fluid collection was found in the upper abdomen, subhepatic area, flanks, and the pelvic cavity. Imaging also revealed the presence of a ruptured abdominal mass (Figure 3). The exploratory laparotomy discovered $3000 \mathrm{ml}$ of blood in the abdominal cavity. The liver was non-cirrhotic, and there was an actively bleeding invasive tumor in the left lateral triangular ligament of the liver. The tumor was resected with an appropriate margin and the specimen was histologically confirmed as a $5-\mathrm{cm}$ HCC with negative margin. The post-operative course was unremarkable, and the patient was discharged on the 10th day post-surgery.

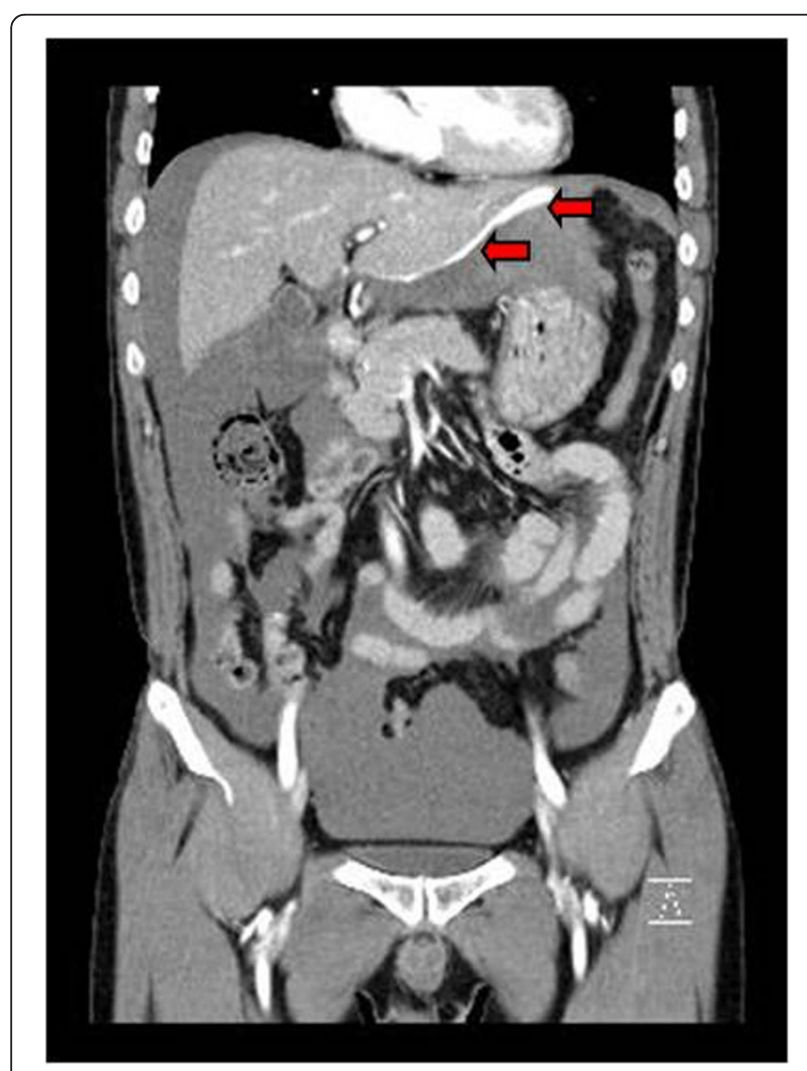

Figure 1 A contrast extravasation is shown from a mass like lesion on the lateral border of the liver (arrow) and hemoperitoneum.

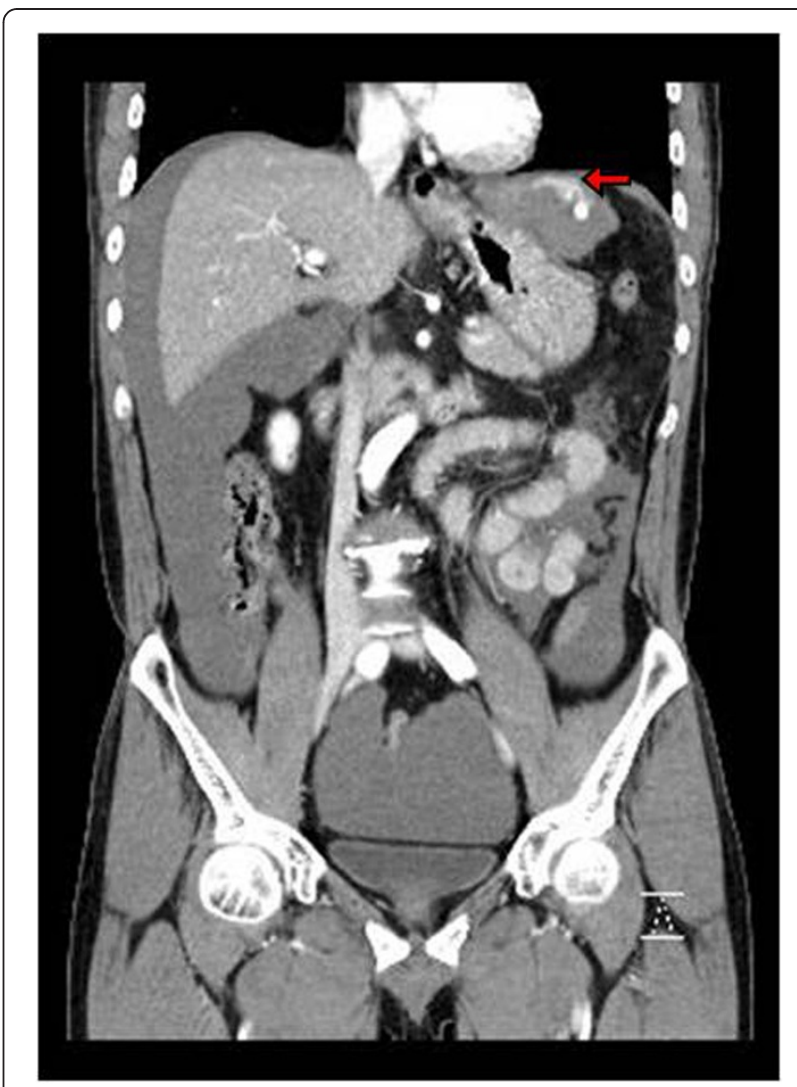

Figure 2 Abdominal CT showes diaphragm invasion of the mass like lesion (arrow).

\section{Discussion}

$\mathrm{HCC}$ is the most common primary malignant tumor of the liver $[1,2]$. Lai and W. Y. Lau analyzed literature published between 1970 and 2004 and found 1500 published cases of spontaneous HCC rupture [2]. This complication is observed in $3 \%$ of the Western population and in $14 \%$ of the Asian population, and mortality ranges between 25 and $75 \%[2,11]$. The mechanism behind the spontaneous rupture of $\mathrm{HCC}$ remains unclear but a number of hypotheses to explain this phenomenon have been published. Possible etiological factors include subcapsular location, tumor dimensions, portal hypertension, tumor necrosis, local increase in venous pressure due to outflow reduction caused by neoplastic invasion, and previous vascular injury which might predispose a patient to HCC rupture and to the rupture of smaller lesions in other locations [12,13]. Usually, the initial symptom is sudden epigastric or right hypochondrial pain. Some patients present with shock, and most have signs of peritonitis, abdominal distension or both. Patients also often present paracentesis-positive with blood-stained ascites [14]. In the presented case, the patient complained of acute abdominal pain and distension. Preoperative diagnosis of HCC rupture is difficult in patients with no previous history of cirrhosis or HCC. 

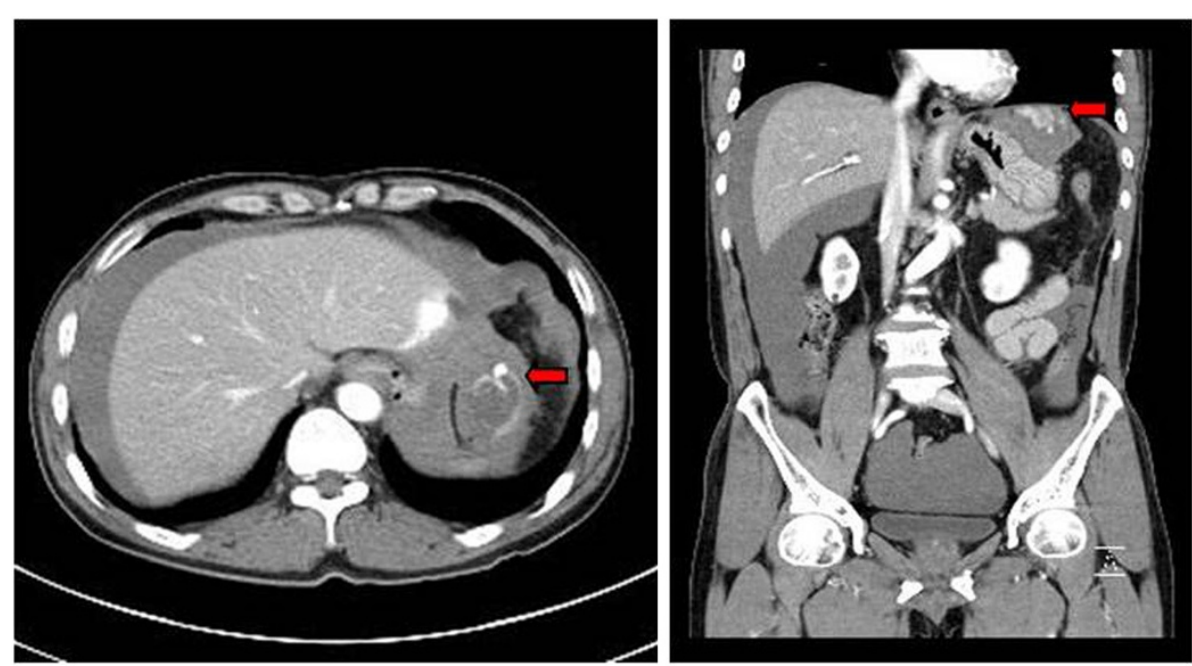

Figure 3 A liver surrounded by a large volume of fluid is seen. An approximately $4 \mathrm{~cm}$ sized low density lesion is located in the periphery of the lateral segment (arrow).

Vergara et al. reported that an accurate preoperative diagnosis of ruptured HCC was predicted in only $25 \%$ of cases, despite shock being present in $33-90 \%$ of the patients [15]. Doppler ultrasound and CT imaging are useful in delineating hemoperitoneum and liver tumors and $\mathrm{CT}$ is specifically useful in detecting $\mathrm{HCC}$ rupture by visualizing the tumor and blood loss. The peripheral location and protrusion of the tumor and discontinuity of the hepatic surface and surrounding hematoma with high attenuation on $\mathrm{CT}$ are very helpful signs in the diagnosis of ruptured HCC [16]. In this case study, contrast extravasation of the tumor and pooling of blood at the periphery of the liver due to hemoperitoneum were helpful in establishing the diagnosis. The management of ruptured HCC is achieved by many techniques depending on the stability of the patient. If the patient is hemodynamically stable, conservative treatment with close monitoring and correction of coagulopathy is the gold standard of care [17]. On the other hand, if the patient is hemodynamically unstable, as in our case, he or she may need surgical interventions after resuscitation. These include transarterial embolization, perihepatic packing, suture plication, absolute alcohol injection, hepatic artery ligation (HAL) or emergency lobe resection. Surgical interventions also depend on the condition of the liver, the size of the tumor and its location. Perihepatic packing is preferred in a bleeding tumor located near the diaphragm but the packing should not be left in for more than 36-72 $\mathrm{h}$ due to risk of infection [2]. Tumor blood supply comes mainly from the hepatic artery, and the efficacy of HAL is estimated to be $68-100 \%$, with mortality as high as $77 \%$ [2]. Due to the risk of liver damage, selective HAL is preferred. One-stage emergency liver resection simultaneously stops bleeding and definitively treats HCC. The resection index in patients with a ruptured HCC ranges between 12.5 and 31\%, and these procedures have a high mortality rate due to inadequate knowledge of the functional hepatic reserve (hemorrhagic shock condition). Reported mortality ranges between 16.5 and $100 \%$, depending on the institution [2] and many authors consequently prefer staged liver resection after initial bleeding control. The resection index mentioned above ranged between 21 and 56\%, while postoperative morality was reported between 0 and $9 \%$. Therefore, one-staged liver resection in ruptured HCC cases should only be performed in easily accessible tumors and only in patients without liver cirrhosis [2]. In our case, the diagnosis of HCC was accidental, and the patient had no history of hepatic disease. On admission, the patient was hemodynamically unstable but had normal liver function. Hemoperitoneum secondary to hepatic rupture was confirmed by CT imaging, and we proceeded with emergency surgery. However, the tumor's advanced stage made it difficult to access and isolate since it was already infiltrating the diaphragm. Direct diaphragmatic invasion of HCC is found in $10 \%$ to 13\% of patients with HCC [10]. To date, 7 retrospective studies and 2 case reports in the English literature report that a total of 162 patients with HCC direct invasion to the diaphragm have undergone en bloc resection or blunt dissection (Table 1). Lau et al. and Lin et al. reported no significant differences in the surgical morbidity and mortality between patients who underwent a traditional hepatectomy and those who had diaphragm resection $[18,19]$. Yamashita et al. reported no significant difference in short- or longterm surgical impacts between patients who received en bloc resection and those who had blunt dissection and suggested that surgeons should consider the possibility of tearing the HCC during blunt dissection between the tumor and the diaphragm [20]. Leung et al. have reported that a 
Table 1 Reports on diaphragm invasion of HCC

\begin{tabular}{llcl}
\hline Author & Year & Number of cases & En bloc resection or Blunt dissection \\
\hline Jeng et al. [22] & 1994 & 8 & En bloc resection (all) \\
\hline Wu et al. [23] & 1994 & 14 & N/A' - Preoperative TAE and resection (all) \\
\hline Lau et al. [19] & 1995 & 14 & En bloc resection (all) \\
\hline Tung et al. [24] & 1996 & 16 & En bloc resection (all) \\
\hline Leung et al. [21] & 2001 & 28 & En bloc resection (all) \\
\hline Lin et al. [18] & 2005 & 53 & En bloc resection (all) \\
\hline Kaur et al. [25] & 2008 & 1 & En bloc resection \\
\hline Yamashita et al. [20] & 2011 & 27 & En bloc resection $(n=13)$ Blunt dissection $(n=14)$ \\
\hline Maruyama et al. [26] & 2012 & 1 & En bloc resection
\end{tabular}

${ }^{1}$ not available.

resection margin of $1 \mathrm{~cm}$ was the only significant prognostic factor for poor disease-free survival after en bloc resection [21]. However, Lin et al. pointed out that there was a possibility of increased intraoperative blood loss and a longer surgery when the diaphragm was resected [18]. Thus, it is necessary to set a surgical plan for unpredictable HCC rupture with direct diaphragm invasion in a situation of emergency laparotomy such as our case. In our case, the patient was saved by the prompt identification of the ruptured HCC and good liver function without liver cirrhosis..

\section{Conclusion}

The prognosis of spontaneous rupture of $\mathrm{HCC}$ is poor with a high hospital mortality rate. A peripherally located large HCC lesion is clinically prone to grossly involve the diaphragm, either by dense adhesion or as a rare result of histological invasion. In such cases, en bloc resection of the diaphragm seems appropriate; however, such extensive surgery is thought to present too high a risk of damage during the postoperative course, especially in emergency operation. For hemoperitoneum patients with unpredictable HCC rupture and diaphragm invasion, physicians should establish a therapeutic plan with consideration of a surgical approach.

\section{Consent}

Written informed consent was obtained from the patient for publication of this case report and any accompanying images. A copy of the written consent is available for review by the editor-in-chief of this journal.

\section{Competing interests}

The authors declare that they have no competing interests.

\section{Authors' contributions}

MHY coordinated the team, helped in literature research and edited the final version of the manuscript. PKK collected the information and wrote the article SIY researched the literature and wrote the article. All authors read and approved the final manuscript.

Received: 4 July 2012 Accepted: 12 September 2012

Published: 21 September 2012

\section{References}

1. Altekruse SF, McGlynn KA, Reichman ME: Hepatocellular carcinoma incidence, mortality, and survival trends in the United States from 1975 to 2005. J Clin Oncol 2009, 27(9):1485-1491.

2. Lai EC, Lau WY: Spontaneous rupture of hepatocellular carcinoma: a systematic review. Arch Surg 2006, 141(2):191-198.

3. Chearanai O, Plengvanit U, Asavanich C, Damrongsak D, Sindhvananda K Boonyapisit S: Spontaneous rupture of primary hepatoma: report of 63 cases with particular reference to the pathogenesis and rationale treatment by hepatic artery ligation. Cancer 1983, 51(8):1532-1536.

4. Clarkston W, Inciardi M, Kirkpatrick S, McEwen G, Ediger S, Schubert T: Acute hemoperitoneum from rupture of a hepatocellular carcinoma. J Clin Gastroenterol 1988, 10(2):221-225.

5. Miyamoto M, Sudo T, Kuyama T: Spontaneous rupture of hepatocellular carcinoma: a review of 172 Japanese cases. Am J Gastroenterol 1991, 86(1):67-71.

6. Liu CL, Fan ST, Lo CM, Tso WK, Poon RT, Lam CM, Wong J: Management of spontaneous rupture of hepatocellular carcinoma: single-center experience. J Clin Oncol 2001, 19(17):3725-3732.

7. Dewar GA, Griffin SM, Ku KW, Lau WY, Li AK: Management of bleeding liver tumours in Hong Kong. Br J Surg 1991, 78(4):463-466.

8. Yoshida H, Onda M, Tajiri T, Umehara M, Mamada Y, Matsumoto S, Yamamoto K, Kaneko M, Kumazaki T: Treatment of spontaneous ruptured hepatocellular carcinoma. Hepatogastroenterology 1999, 46(28):2451-2453.

9. Starzl TE, Koep LJ, Weil R 3rd, Lilly JR, Putnam CW, Aldrete JA: Right trisegmentectomy for hepatic neoplasms. Surg Gynecol Obstet 1980, 150(2):208-214.

10. Yuki K, Hirohashi S, Sakamoto M, Kanai T, Shimosato Y: Growth and spread of hepatocellular carcinoma. a review of 240 consecutive autopsy cases. Cancer 1990, 66(10):2174-2179.

11. Battula N, Madanur M, Priest O, Srinivasan P, O'Grady J, Heneghan MA, Bowles M, Muiesan P, Heaton N, Rela M: Spontaneous rupture of hepatocellular carcinoma: a Western experience. Am J Surg 2009, 197(2):164-167.

12. Castells L, Moreiras M, Quiroga S, Alvarez-Castells A, Segarra A, Esteban R, Guardia J: Hemoperitoneum as a first manifestation of hepatocellular carcinoma in western patients with liver cirrhosis: effectiveness of emergency treatment with transcatheter arterial embolization. Dig Dis Sci 2001, 46(3):555-562.

13. Zhu LX, Geng XP, Fan ST: Spontaneous rupture of hepatocellular carcinoma and vascular injury. Arch Surg 2001, 136(6):682-687.

14. Hai L, Yong-Hong P, Yong F, Ren-Feng L: One-stage liver resection for spontaneous rupture of hepatocellular carcinoma. World J Surg 2005, 29 (10):1316-1318.

15. Vergara V, Muratore A, Bouzari H, Polastri R, Ferrero A, Galatola G, Capussotti $L$ : Spontaneous rupture of hepatocelluar carcinoma: surgical resection and long-term survival. Eur J Surg Oncol 2000, 26(8):770-772.

16. Kim PN, Kim IY, Bae WK, Lee BH: Computed tomographic findings of ruptured hepatic malignancy. Gastrointest Radiol 1991, 16(4):334-336

17. Ribeiro Junior MA, Chaib E, Saad WA, D'Albuquerque LA, Cecconello I: Surgical management of spontaneous ruptured hepatocellular adenoma. Clinics (Sao Paulo) 2009, 64(8):775-779. 
18. Lin MC, Wu CC, Chen JT, Lin CC, Liu TJ: Surgical results of hepatic resection for hepatocellular carcinoma with gross diaphragmatic invasion. Hepatogastroenterology 2005, 52(65):1497-1501.

19. Lau WY, Leung KL, Leung TW, Liew CT, Chan M, Li AK: Resection of hepatocellular carcinoma with diaphragmatic invasion. Br J Surg 1995, 82(2):264-266.

20. Yamashita Y, Morita K, Iguchi T, Tsujita E, Soejima Y, Taketomi A, Maehara Y: Surgical impacts of an en bloc resection of the diaphragm for hepatocellular carcinoma with gross diaphragmatic involvement. Surg Today 2011, 41(1):101-106.

21. Leung KF, Chui AK, Leung KL, Lai PB, Liew CT, Lau WY: Clinicopathological study of hepatocellular carcinoma with diaphragmatic involvement. $\mathrm{Br}\rfloor$ Surg 2001, 88(5):681-682.

22. Jeng KS, Chen BF, Lin HJ: En bloc resection for extensive hepatocellular carcinoma: is it advisable? World J Surg 1994, 18(6):834-839.

23. Wu CC, Ho WL, Liu TJ: Hepatocellular carcinoma with adjacent organ extension: the enhancement of preoperative transcatheter arterial embolization and the results of surgical resection. Surg Today 1994, 24(10):882-888.

24. Tung WY, Chau GY, Loong CC, Wu JC, Tsay SH, King KL, Huang SM, Chiu JH, Wu CW, Lui WY: Surgical resection of primary hepatocellular carcinoma extending to adjacent organ(s). Eur J Surg Oncol 1996, 22(5):516-520.

25. Kaur R, Abdullah B, Rajasingam V: Hepatocellular carcinoma with extension to the diaphragm, falciform ligament, rectus abdominis and paraumbilical vein. Biomed Imaging Interv J 2008, 4(4):e37.

26. Maruyama H, Yoshida H, Hirakata A, Matsutani T, Yokoyama T, Suzuki S, Matsushita A, Sasajima K, Kikuchi Y, Uchida E: Surgical treatment of a patient with diaphragmatic invasion by a ruptured hepatocellular carcinoma with biliary and portal venous tumor thrombi. J Nihon Med sch 2012, 79(2):147-152.

doi:10.1186/1749-7922-7-30

Cite this article as: Park et al.: One stage resection of spontaneous rupture of hepatocellular carcinoma in the triangular ligament with diaphragm invasion: case report and review of the literature. World Journal of Emergency Surgery 2012 7:30.

\section{Submit your next manuscript to BioMed Central and take full advantage of:}

- Convenient online submission

- Thorough peer review

- No space constraints or color figure charges

- Immediate publication on acceptance

- Inclusion in PubMed, CAS, Scopus and Google Scholar

- Research which is freely available for redistribution 